\title{
Composition and Fatty Acid Profile of Goat Meat Sausages with Added Rice Bran
}

\author{
Fatemeh Malekian, Margarita Khachaturyan, Sebhatu Gebrelul, and James F. Henson
}

Southern University Agricultural Research and Extension Center, P.O. Box 10010, Baton Rouge, LA 70813, USA

Correspondence should be addressed to Fatemeh Malekian; fatemeh_malekian@suagcenter.com

Received 4 December 2013; Revised 28 February 2014; Accepted 15 March 2014; Published 16 April 2014

Academic Editor: Alejandro Castillo

Copyright ( 2014 Fatemeh Malekian et al. This is an open access article distributed under the Creative Commons Attribution License, which permits unrestricted use, distribution, and reproduction in any medium, provided the original work is properly cited.

A scientific consensus on the relationship between obesity, obesity related diseases, and diet has emerged. One of the factors is overconsumption of the red meats such as pork and beef. Goat meat has the potential to replace these traditionally consumed meats. Rice bran is a rich source of antioxidants such as vitamin E. In this study, goat meat sausages were formulated to contain 0 , 1.5 or 3 percent stabilized rice bran. Proximate and fatty acid composition, $\alpha$-tocopherol, cholesterol concentration, and antioxidant activities of cooked goat meat sausages containing varying percentages of rice bran were measured. Data were analyzed using a fixed effects model. The fat percentage in the goat meat sausages increased in response to increasing rice bran percentages $(P<0.001)$. Saturated fatty acids concentration decreased linearly $(P<0.01)$, while unsaturated fatty acids and omega-3 and omega-6 fatty acids increased linearly in response to increasing rice bran percentages $(P<0.05)$. The concentration of $\alpha$-tocopherol in sausages increased linearly in response to increasing rice bran percentages $(P<0.01)$. Also, antioxidant activity increased linearly in sausages in response to added rice bran $(P<0.01)$. The cholesterol concentration of sausages did not vary significantly in response to added rice bran.

\section{Introduction}

A scientific consensus on the relationship between diet and obesity related diseases such as diabetes, heart disease, stroke, and some forms of cancer has been documented [1]. The obesity rate in Louisiana is $28.9 \%$, which is the eighth highest in the USA. Furthermore, Louisiana is in the top seven states in obesity-related medical expenditure [2]. Foods from animal sources have been a part of human diets for years. Even though the percentage of fat in meat has decreased in recent years, the polyunsaturated to saturated fatty acid ratio in meat is usually less than 0.2 when the fat content is above $2 \%$ [3]. Blood cholesterol level depends less on the intake of cholesterol from foods and more on the amount of saturated fats consumed, especially the ratio of polyunsaturated to saturated fats [4]. A study has shown that with proper dietary intervention, the mean blood cholesterol level of $90 \%$ of a test population was reduced by $3 \%$ to $23 \%$ [5]. Dietary habits are major factor in the development of obesity and cardiovascular heart diseases.
During the past few decades, epidemiological studies have suggested that a healthy diet and lifestyle are critical for the prevention of many diseases such as breast cancer. Breast cancer is one of the most common cancers and is the second leading cause of death in women. Dietary fat is one of the most studied factors. The most promising dietary fatty acids to reduce the risk of breast cancer are omega-3 polyunsaturated fatty acids [1].

Lean goat meat is low in fat and saturated fatty acids, but high in unsaturated fatty acids such as linoleic and oleic that have been shown to possess hypocholesteremic properties $[6,7]$. The chemical composition of goat meat is as follows: moisture $74.2-76.0 \%$; protein $20.6-22.3 \%$; fat $0.6-2.6 \%$; ash $1.1 \%$ [8]. Goat meat cuts have protein levels comparable to similarly prepared beef, lamb, and veal but have lower fat content [9]. In addition, the percentage of saturated fat in goat meat is lower than in chicken, beef, pork, or lamb $[10,11]$.

Considering its high nutritional value and its greater unsaturated to saturated fatty acid ratio, goat meat has the potential to improve the health of susceptible populations 
without taking meat products out of their daily diet. Consumption of goat meat is becoming popular and is often available at the fine dining level [12].

Currently, there is an increased interest in the use of dietary antioxidants, including vitamins $\mathrm{C}$ and $\mathrm{E}$, to prevent cardiovascular diseases [13]. There are many natural antioxidants which can be added to the meat products to increase their health benefits. Some examples are rosemary oil [14], rice bran oil [15], rice bran oil plus rice bran fiber [16], oat bran [6], and oat flour [17]. A number of studies have shown that vitamin E, as a chain-breaking antioxidant, prevents the propagation of free radical reactions [18-20]. Vitamin E inhibits lipid peroxidation in vitro and in vivo because of its radical scavenging and antioxidant properties [21].

As a major isoform of Vitamin E, $\alpha$-tocopherol is effective in vivo only against free radical-mediated oxidation. It inhibits LDL oxidation in vitro and has therapeutic effects against atherosclerosis [22]. The rice bran oil antioxidants are very efficient in reducing low density lipoprotein (LDL) and total serum cholesterol [23]. Rice bran oil contains about $0.1-0.14 \%$ vitamin E components and $0.9-2.9 \%$ oryzanol. The concentrations can vary substantially according to the origin of the rice bran $[24,25]$. Vitamin $\mathrm{E}$ is a generic term for a group of four tocopherols $\left(\alpha-, \beta-, \gamma\right.$ - and $\left.\Delta_{-}\right)$and four tocotrienols $\left(\alpha-, \beta-, \gamma\right.$ - and $\left.\Delta^{-}\right)$, of which $\alpha$-tocopherol has the highest biological activity [26].

Rice bran, a byproduct of the rice milling process, is a naturally rich source of antioxidants along with vitamins and minerals. Additionally, it contains $14-16 \%$ protein without gluten, $12-23 \%$ fat, and $8-10 \%$ crude fiber [27]. Nutritional studies in animals and humans have demonstrated the cholesterol lowering potential of rice bran and rice bran fractions $[28,29]$. Rice bran fractions such as rice bran oil and soluble fiber are crucial factors in the regulation of plasma cholesterol levels, and the insoluble fiber plays an important role in intestinal regulation $[23,30]$. Rice bran also has some beneficial dietary components. These components lowered blood pressure and improved the lipid profile by decreasing the low density lipoprotein (LDL) level in hypertensive rats [31]. Substituting saturated fatty acids in the diet with unsaturated fatty acids such as oleic, linoleic, and linolenic acid lowered low-density lipoprotein-cholesterol in human subjects [32]. The protein in rice bran does not contain gluten, therefore, it is a healthy food choice for people with celiac disease. Approximately, 1 in 133 people in the United States has celiac disease, an immune-mediated disorder associated with gluten, a protein present in wheat, barley, and rye. Most affected individuals experience a remission of the disease after excluding gluten from their diets [33]. In June 2008, the United States Department of Agriculture Food Safety and Inspection Service (USDA FSIS) approved the use of stabilized rice bran as a binder to a maximum of $3.5 \%$ in various meat products such as sausage, meatballs, meat loaf, and meat patties [34]. Stabilized rice bran can hold moisture up to three times its weight which can contribute to the juiciness of the goat meat products. Rice bran also has a meatlike texture when it is cooked [35].

The goal of this study was to formulate a healthy goat meat sausage with a higher level of antioxidant activity, a higher level of unsaturated fatty acids, and a lower fat content compared to beef sausages as well as a gluten free product by incorporating varying amounts of stabilized rice bran to the formulation. Nutritional characteristics of raw and cooked goat meat sausages with added rice bran were determined by analyzing the samples for proximate composition and cooked goat meat sausage for fatty acid composition, $\alpha$-tocopherol and cholesterol concentration, and antioxidant activity.

\section{Materials and Methods}

2.1. Preparation of Sausages. Goats were reared at the Southern University Agricultural Research and Extension Center (SUAREC) goat farm until slaughter and preparation of products. All meat was prepared in the state inspected Southern University Meat Processing Laboratory. Shoulder, leg, and other parts of one-to-three-year-old goats were deboned and ground.

Rice bran was obtained from Planters Rice Mill in Abbeville, LA and stabilized using microwave heat [36]. The stabilized rice bran was sieved with a 20 mesh screen in order to remove broken rice and husks and to obtain a uniform particle size.

Chili seasoning was obtained from Symrise Inc., Teterboro, NJ. Chili seasoning ( $3 \%$ by weight), salt ( $1.6 \%$ by weight), and water (3.3\% by weight) were incorporated into the ground goat meat. Chili seasoning and salt were added for taste, rice bran was added as a binder, and water was added to provide moisture in the mix. The meat samples were divided into three groups. Group 1 was the control with $0 \%$, group 2 with $1.5 \%$, and group 3 with $3 \%$ (by weight) stabilized rice bran. The meat/rice bran mixtures were packed into collagen casing. Raw sausages were cooked in a preheated $\left(53.3^{\circ} \mathrm{C}\right)$ "Koch" stainless steel cooker/smoker (Koch Supply, North Kansas city, MO). The temperature was increased manually at $2.7^{\circ} \mathrm{C}$ per hour until the temperature of the cooker reached $65.5^{\circ} \mathrm{C}$. The smoker was then turned on and the temperature increased until the internal temperature of the sausages reached $70^{\circ} \mathrm{C}$ for at least 15 seconds. The cooking and smoking time was 6 to 7 hours. Approximately, $500 \mathrm{~g}$ of each raw and cooked sausage were homogenized in a Robot Coup R2 food processor (Robot Coup USA Inc., Ridgeland, MS) for two minutes to obtain a homogeneous sample. Three aliquots were prepared for the raw and cooked sausages and were frozen at $-20^{\circ} \mathrm{C}$ until further analysis.

2.2. Proximate Analysis. On the day of analysis, samples were taken out of the freezer early in the morning and were thawed at room temperature. Samples were analyzed using standard American Official of Analytical Chemists (AOAC) approved methods (983.23, 992.15, 920.15, and 985.14) with modifications [37]. Lipids were extracted using a chloroform/methanol solution with butylated hydroxytoluene (BHT), as an antioxidant, and determined gravimetrically. Aliquots were taken from lipid extracts for determination of fatty acids. Protein content was determined using thermal conductivity on a Series II Nitrogen Analyzer 2410 (PerkinElmer Instruments, Norwalk, CT). Ash content was 
determined with using a Phoenix microwave furnace (CEM corp., Matthews, NC). Moisture content was determined using a Smart system 5 (CEM corp., Matthews, CT). Percentage of carbohydrate was determined by difference using formula: \%Carbohydrate $=100-(\%$ Moisture $+\%$ Fat + $\%$ Ash $+\%$ Proteins). Each sample was run in triplicate.

2.3. Fatty Acid Determination. Lipid extracts aliquots (prepared during total lipid extraction according to Section 2.2) were used for the determination of fatty acid composition using a Varian Saturn 2100 (Agilent Technologies Inc. Wilmington DE) Gas Chromatography/Mass Spectrophotometer (GC/MS) with a fused silica column $(30 \times 0.25 \mathrm{~mm})$ [38]. GLC-490 Reference Standard and C23:0 methyl esters (Internal Standard) were purchased from Nu-Check Prep. Inc. (Elysian, Minnesota, USA) and used for determination of fatty acids. Each sample was run in triplicate.

\subsection{Simultaneous Determination of $\alpha$-Tocopherol and Choles-} terol. Cholesterol and $\alpha$-tocopherol were measured simultaneously on an 1100 Agilent High Performance Liquid Chromatography (HPLC) system (Agilent Technologies Inc. Wilmington DE). Homogenized sausage samples were prepared, extracted and quantified [39]. A ZORBAX RX-SIL $5 \mu \mathrm{m}, 4.8 \times 250 \mathrm{~mm}$ column was used. The mobile phase was composed of $99 \%$ hexane and 1\% isopropyl alcohol (HPLC grade) at a flow rate of $0.5 \mathrm{~mL} / \mathrm{min}$. The total running time was 12 minutes. The detector was a diode array detector (DAD) operating at $\lambda=202 \mathrm{~nm}$. The injection volume was $5 \mu \mathrm{L}$ with a needle cleansing system and thermostat temperature of $20^{\circ} \mathrm{C}$. The $\alpha$-tocopherol and cholesterol standards and other chemicals were purchased from Sigma Aldrich Co. (St. Louis, MO). Standards were dissolved in hexane. Solutions with 500 ppm of each standard were diluted volumetrically. A calibration curve for each component was made. Analytes were detected using $\mathrm{DAD}$ and peak identification which was accomplished by comparing the retention times and HPLC peaks with those obtained from standard solution of mixture analyzed under the same conditions. Quantitative determination was performed using the standard curve. Each sample was run in triplicate.

2.5. Antioxidant Activity Determination. The DPPH (2,2diphenyl-1-picrylhydrazyl) free radical scavenging method was used to measure the antioxidant activity [40] with a slight modification. The chloroform/methanol lipid extraction solution without BHT was used for extraction of components having antioxidant activity. Absorption of the intermediate colored complex was measured on UV-Vis Beckman Coulter spectrophotometer (Loveland, Colorado) at $515 \mathrm{~nm}$ and the results were expressed in terms of micromole equivalents of Trolox (6-hydroxy-2,5,7,8-tetramethylchroman-2-carboxylic acid) per 100 grams of sample [40]. The DPPH radical and Trolox were purchased from Sigma Aldrich Co. (St. Louis, $\mathrm{MO})$. Each sample was run in triplicate.

2.6. Experimental Design and Statistical Analysis. The study was conducted as a two-factor experiment in a completely randomized design with three replicates. The two factors were sausage preparation (raw or cooked) and three levels of rice bran inclusion ( $0,1.5$ and $3 \%)$. The experimental data were analyzed using PROC GLM of SAS version 9.3 [41]. The data were fitted to a fixed model with the factors sausage preparation and rice bran level treated as fixed effects. The treatment means were compared using the least squares means method of PROC GLM. The effects of the rice bran percentages were compared with trend analysis using orthogonal polynomial contrasts.

\section{Results and Discussion}

3.1. Proximate Analyses. The results of the proximate analyses of stabilized rice bran, goat meat, and chili seasoning are presented in Table 1. The proximate analysis percentages for rice bran are similar to those found in the literature [42], but the percentages for goat meat analysis differed from those obtained by Devendra [8]. Goat meat moisture and protein percentages were lower than those reported by Devendra, while fat percent was higher and ash percent was similar [8]. According to Devendra, goat meat had lower fat content than fat content in this study because in their study the tissue was more concentrated in viscera than the muscle. In this study, a mixture of shoulder, leg, and other parts of meats of oneto-three-year-old goats was used, while Devendra used meat from kids (young goat). The composition of meat depends on the age of animal and the part of the animal used [43].

The proximate analyses of sausages with added rice bran are presented in Table 2. The moisture content of the raw sausages decreased slightly in response to increased rice bran percentage. In contrast, the moisture content of cooked sausages decreased linearly in response to increasing rice bran percentages. This was due to the addition of ample water to the mixture before rice bran is added at three different levels and 6-7 hours of cooking and smoking process. Also, the results of this study for cooked goat meat sausage are similar to other studies [6]. The percentages of fat, ash and protein were greater in the cooked sausages than the raw sausages. This probably was due to the moisture loss during the treatment and cooking process. The fat content of both raw and cooked sausages increased linearly in response to increasing rice bran percentages as a result of addition of fat from rice bran. Thus, sausages with added rice bran might have a more beneficial fatty acid composition in regard to more mono- and poly unsaturated fatty acids [15] as discussed in Section 3.2. The ash percent of raw sausages did not vary significantly across the rice bran percentage, The ash percent of cooked sausages decreased linearly in response to the increasing rice bran percentage, even though the variation among means was small. This could be due to a very sensitive equipment Phoenix microwave furnace (CEM corp., Matthews, NC), the variability within the replicates were so small that significant differences $(P<0.001)$ were detected. There was no significant effect of added rice bran on the protein content of raw sausages and cooked sausages. On the other hand, the cooking and smoking process increased the percentage of protein. The carbohydrate percentage of 
TABLE 1: Proximate composition of stabilized rice bran, goat meat, and chili seasoning (Means \pm s.e.).

\begin{tabular}{lccc}
\hline Proximate analysis & Stabilized rice bran & $\begin{array}{c}\text { Goat meat } \\
\text { (\% by weight) }\end{array}$ & $\begin{array}{c}\text { Chili seasoning } \\
\text { Moisture }\end{array}$ \\
Fat & $18.4 \pm 0.08$ & $70.8 \pm 0.20$ & $4.3 \pm 0.50$ \\
Ash & $15.6 \pm 0.10$ & $10.9 \pm 0.46$ & $5.2 \pm 0.01$ \\
Protein & $9.6 \pm 0.03$ & $0.9 \pm 0.01$ & $13.1 \pm 0.04$ \\
Carbohydrates & $11.5 \pm 0.18$ & $14.6 \pm 0.78$ & $10.0 \pm 0.08$ \\
\hline
\end{tabular}

TABLE 2: Proximate composition of raw and cooked goat meat sausages with added rice bran (Means \pm s.e. $)^{\S}$.

(a)

\begin{tabular}{|c|c|c|c|c|c|}
\hline \multirow{4}{*}{ Proximate analysis } & \multicolumn{5}{|c|}{ Raw } \\
\hline & \multicolumn{3}{|c|}{ Percent rice bran } & \multirow{3}{*}{ Mean $^{\dagger}$} & \multirow{3}{*}{ Linear effect ${ }^{\ddagger}$} \\
\hline & 0 & 1.5 & 3 & & \\
\hline & & (\% by weight) & & & \\
\hline Moisture $^{\#}$ & $72.2^{\mathrm{a}} \pm 0.009$ & $70.9^{\mathrm{a}} \pm 0.09$ & $70.1^{\mathrm{a}} \pm 0.04$ & $71.1 \pm 0.31$ & $-{ }^{* * *}$ \\
\hline $\mathrm{Fat}^{\#}$ & $8.9^{b} \pm 0.28$ & $9.7^{\mathrm{b}} \pm 0.35$ & $10.5^{\mathrm{b}} \pm 0.21$ & $9.7 \pm 0.27$ & $+{ }^{* * *}$ \\
\hline Ash & $1.5 \pm 0.01$ & $1.5 \pm 0.01$ & $1.5 \pm 0.02$ & $1.5^{\mathrm{B}} \pm 0.01$ & ns \\
\hline Protein & $13.1 \pm 1.29$ & $13.3 \pm 2.05$ & $11.8 \pm 1.06$ & $12.8^{\mathrm{B}} \pm 0.80$ & ns \\
\hline Carbohydrates & $4.3 \pm 1.14$ & $4.6 \pm 2.08$ & $6.1 \pm 1.32$ & $5.0^{\mathrm{A}} \pm 0.83$ & ns \\
\hline
\end{tabular}

(b)

Cooked

\begin{tabular}{|c|c|c|c|c|c|}
\hline \multirow{3}{*}{ Proximate analysis } & \multicolumn{3}{|c|}{ Percent rice bran } & \multirow{3}{*}{$\operatorname{Mean}^{\dagger}$} & \multirow{3}{*}{ Linear effect } \\
\hline & 0 & 1.5 & 3 & & \\
\hline & & (\% by weight) & & & \\
\hline Moisture $^{\#}$ & $63.6^{\mathrm{b}} \pm 0.50$ & $62.9^{\mathrm{b}} \pm 0.13$ & $58.3^{\mathrm{b}} \pm 0.04$ & $61.6 \pm 0.86$ & $-{ }^{* * *}$ \\
\hline $\mathrm{Fat}^{\#}$ & $13.1^{\mathrm{a}} \pm 0.03$ & $12.3^{\mathrm{a}} \pm 0.06$ & $15.1^{\mathrm{a}} \pm 0.20$ & $13.5 \pm 0.42$ & $t^{* * *}$ \\
\hline Ash & $2.1 \pm 0.01$ & $2.0 \pm 0.02$ & $2.0 \pm 0.02$ & $2.0^{\mathrm{A}} \pm 0.02$ & $-{ }^{* * *}$ \\
\hline Protein & $20.5 \pm 1.00$ & $21.1 \pm 0.20$ & $21.6 \pm 0.32$ & $21.1^{\mathrm{A}} \pm 0.34$ & ns \\
\hline Carbohydrates & $1.0 \pm 1.00$ & $1.7 \pm 0.40$ & $3.0 \pm 0.56$ & $1.8^{\mathrm{B}} \pm 0.46$ & ns \\
\hline
\end{tabular}

${ }^{\S}$ All sausages contain chili seasoning ( $3 \%$ by weight) and salt ( $1.6 \%$ by weight).

${ }^{\dagger}$ Different upper case letters (A and B) following a raw and cooked mean (across percent rice bran levels) indicates that those two means differ $(P<$ $0.05)$.

${ }^{\#}$ Moisture and Fat exhibited a significant preparation by percent rice bran interaction; therefore raw and cooked means were not compared. Different lower case letters ( $\mathrm{a}$ and $\mathrm{b}$ ) following a percent rice bran mean (within a percent rice bran level) indicates that raw and cooked differ $(P<0.05)$.

${ }^{\ddagger}$ The - sign indicates a negative response and the + sign a positive response to increasing percent rice bran levels.

$\ddagger *, * * * * *$ indicates the linear effect, significant at the $0.05,0.01,0.001$ level of probability, respectively. ns: not significant.

raw and cooked sausages did not changed significantly in response to the increasing rice bran percentages. This could be due to cooking and smoking process. Cooking process decreased the carbohydrate percentage from raw to cook. In this study we did not measure cooking yield due to complexity of the cooking and smoking process.

3.2. Fatty Acids. Fatty acids are important components of meat lipids [10] which can have an important influence on human plasma cholesterol level. For instance, saturated fatty acids increase cholesterol levels in contrast to total monounsaturated fatty acids (MUFA) and total polyunsaturated fatty acids (PUFA). Not all saturated fatty acids have the same influence on the cholesterol level; C16:0 and C14:0 can increase cholesterol levels, while C18:0 does not have such effect [10].

Fatty acid content, as percentages of total fatty acids, for goat meat reported in the literature are oleic acid $(\mathrm{C} 18: 1)$ $28-50 \%$, palmitic (C16:0) 15-31\%, stearic (C18:0) 6-17\%, and linoleic (C18:2) 4-15\% [10]. The high concentration of C18:0 in goat meat will not increase cholesterol levels in human, and more importantly, the ratio of $(\mathrm{C} 18: 0+\mathrm{C} 18: 1)$ to $\mathrm{C} 16: 0$ could have beneficial health effects when it falls between 2 and 3 [10]. Meat can be also classified to have health benefits by concentration of desirable fatty acids (DFA) which include the total of C18:0 and all unsaturated fatty acids. These DFA are considered to have either neutral or cholesterol lowering effects [10]. 
TABLE 3: Fatty acid composition of cooked goat meat sausages with added rice bran (Means \pm s.e. $)^{\S}$.

\begin{tabular}{|c|c|c|c|c|}
\hline \multirow{2}{*}{ Fatty acids } & \multicolumn{3}{|c|}{ Percent rice bran } & \multirow{2}{*}{ Linear effect ${ }^{\ddagger}$} \\
\hline & 0.0 & 1.5 & 3.0 & \\
\hline \multicolumn{5}{|c|}{ Saturated fatty acids } \\
\hline C14:0 & $2.37 \pm 0.04$ & $2.48 \pm 0.01$ & $2.28 \pm 0.03$ & ns \\
\hline $\mathrm{C} 16: 0$ & $24.40 \pm 0.77$ & $23.75 \pm 0.20$ & $23.19 \pm 0.11$ & ns \\
\hline C18:0 & $38.25 \pm 0.14$ & $34.76 \pm 0.35$ & $36.00 \pm 0.10$ & $-{ }^{* * *}$ \\
\hline \multicolumn{5}{|c|}{ Mono and poly unsaturated fatty acids } \\
\hline C16:1 & $1.17 \pm 0.01$ & $1.41 \pm 0.01$ & $1.27 \pm 0.02$ & $+{ }^{* *}$ \\
\hline C18:1 & $29.51 \pm 0.78$ & $32.52 \pm 0.3$ & $32.09 \pm 0.30$ & $+^{*}$ \\
\hline $\mathrm{C} 18: 2 \mathrm{n} 6$ & $3.02 \pm 0.15$ & $3.56 \pm 0.14$ & $3.67 \pm 0.17$ & $+{ }^{*}$ \\
\hline $\mathrm{C} 18: 3 \mathrm{n} 6$ & $0.27 \pm 0.04$ & $0.32 \pm 0.03$ & $0.27 \pm 0.02$ & ns \\
\hline $\mathrm{C} 18: 3 \mathrm{n} 3$ & $0.30 \pm 0.02$ & $0.38 \pm 0.02$ & $0.46 \pm 0.10$ & ns \\
\hline $\mathrm{C} 20: 2 \mathrm{n} 6$ & $0.03 \pm 0.01$ & $0.03 \pm 0.02$ & $0.06 \pm 0.004$ & $+^{*}$ \\
\hline C20:3n6 & $0.09 \pm 0.01$ & $0.07 \pm 0.01$ & $0.00 \pm 0.00$ & $-{ }^{* * *}$ \\
\hline C20:4n6 & $0.57 \pm 0.06$ & $0.65 \pm 0.02$ & $0.63 \pm 0.03$ & ns \\
\hline C20:5n3 & $0.01 \pm 0.00$ & $0.06 \pm 0.03$ & $0.06 \pm 0.01$ & $++^{* *}$ \\
\hline \multicolumn{5}{|c|}{ Sums and ratios of fatty acids } \\
\hline$\sum$ Sat & $65.02 \pm 0.79$ & $61.00 \pm 0.31$ & $61.48 \pm 0.20$ & $-{ }^{* *}$ \\
\hline$\sum$ MUFA & $30.69 \pm 0.77$ & $33.93 \pm 0.32$ & $33.36 \pm 0.30$ & $+^{*}$ \\
\hline$\sum$ PUFA & $4.28 \pm 0.15$ & $5.07 \pm 0.08$ & $5.15 \pm 0.23$ & $+^{* *}$ \\
\hline DFA & $73.2 \pm 0.80$ & $73.6 \pm 0.19$ & $74.5 \pm 0.12$ & ns \\
\hline$(\mathrm{C} 18: 0+\mathrm{C} 18: 1) / \mathrm{C} 16: 0$ & $2.78 \pm 0.15$ & $2.83 \pm 0.04$ & $2.94 \pm 0.02$ & ns \\
\hline$\sum \mathrm{n} 6$ & $3.97 \pm 0.02$ & $4.63 \pm 0.09$ & $4.64 \pm 0.20$ & $+^{*}$ \\
\hline$\sum \mathrm{n} 3$ & $0.31 \pm 0.02$ & $0.44 \pm 0.02$ & $0.51 \pm 0.09$ & $+^{*}$ \\
\hline$\sum \mathrm{n} 3 / \sum \mathrm{n} 6$ & $0.08 \pm 0.00$ & $0.09 \pm 0.00$ & $0.11 \pm 0.02$ & ns \\
\hline$\sum \mathrm{PUFA} / \sum$ Sat & $0.06 \pm 0.01$ & $0.08 \pm 0.00$ & $0.08 \pm 0.00$ & $++^{* *}$ \\
\hline
\end{tabular}

${ }^{\varsigma}$ All sausages contain chili seasoning ( $3 \%$ by weight) and salt (1.6\% by weight).

${ }^{\ddagger}$ The - sign indicates a negative response and the + sign a positive response to increasing percent rice bran levels.

${ }^{\ddagger}$ Indicates the linear effect, ${ }^{*, * * * * *}$ Significant at the $0.05,0.01,0.001$ level of probability, respectively.

$\sum$ Sat $=$ sum of saturated fatty acids; $\sum$ MUFA $=$ sum of monounsaturated fatty acids; $\sum$ PUFA $=$ sum of polyunsaturated fatty acids.

DFA (Desired fatty acids) $=\mathrm{C} 18: 0+\sum$ MUFA $+\sum$ PUFA; $\sum \mathrm{n} 6=$ sum of omega- 6 fatty acids; $\sum \mathrm{n} 3=$ sum of omega- 3 fatty acids. ns: not significant.

Essential omega- 6 and omega- 3 fatty acids play a crucial role in the human body. They carry fat soluble vitamins and support immune systems. These fatty acids cannot be synthesized by human organisms and need to be consumed in the diet [35]. The C20:4 eicosatetranoic fatty acid is an essential fatty acid [10] which can be derived either from C18:2 linoleic fatty acids or directly from the diet. Goat muscle contains nearly twice as much C20:4 as lamb muscle [10]. The C18:2 and C20:4 fatty acid contents in goat meat used for this study were lower than in the literature which may be explained by the utilization of different parts of the goat and older goats that contain less total PUFA.

The fatty acid compositions of cooked goat meat sausages with added rice bran are presented in Table 3. Goat meat, stabilized rice bran, and chili seasoning were analyzed for fatty acid composition also (data not shown). The fatty acid results for rice bran were comparable to previously published results [36]. The fatty acids composition of goat meat sausages without rice bran was comparable to goat patties without oat bran [6]. The individual fatty acid components and sums and ratios of individual fatty acids are presented as a percentage of total fatty acids. The percentage of total fatty acids of 5 of the 12 individual fatty acids increased linearly in response to the increasing rice bran percentages, while only 2 fatty acids decreased with increased rice bran. The percentage of total fatty acids for the sum of the saturated fatty acids ( $\sum$ Sat) in unmixed rice bran was $22.7 \%$ (data not shown) compared to $65.2 \%$ for goat meat sausage without rice bran as shown in Table 3. Consequently, it was expected that incorporation of rice bran to decrease the saturated fatty acids content of goat meat sausages. In this study, the total saturated fatty acids decreased significantly $(P<0.001)$ in response to increasing rice bran percentage of the goat meat sausages (Table 3). The percentage of total fatty acids for the $\sum$ MUFA in unmixed rice bran was $49.8 \%$ (data not shown) compared to $30.7 \%$ in goat meat sausages without rice bran as shown in Table 3. Therefore, the incorporation of rice bran, into goat meat sausages was expected to increase the $\sum$ MUFA of the goat meat sausages. In this study, the percentage of total fatty acids for $\sum$ MUFA increased significantly $(P<0.05)$ in response to increasing rice bran percentages of the goat meat sausages (Table 3). The percentage of the total fatty acids of the monounsaturated fatty acids C16:1 and C18:1 increased linearly. The percentage of total fatty acids for 3 
TABLE 4: $\alpha$-Tocopherol, cholesterol, and antioxidant activity of rice bran and cooked goat meat sausages with added rice bran $(\text { Means } \pm \text { s.e. })^{\S}$.

\begin{tabular}{|c|c|c|c|c|c|}
\hline & \multicolumn{5}{|c|}{ Goat meat sausage } \\
\hline & \multirow[t]{2}{*}{ Rice bran } & \multicolumn{3}{|c|}{ Percent rice bran } & \multirow[t]{2}{*}{ Linear effect ${ }^{\ddagger}$} \\
\hline & & 0 & 1.5 & 3 & \\
\hline & \multicolumn{5}{|c|}{$(\mathrm{mg} / 100 \mathrm{~g})$} \\
\hline$\alpha$-Tocopherol & $7.37 \pm 0.21$ & $0.96 \pm 0.08$ & $0.99 \pm 0.08$ & $1.40 \pm 0.02$ & $++^{* *}$ \\
\hline \multirow[t]{2}{*}{ Cholesterol } & & $51.4 \pm 0.90$ & $51.4 \pm 1.78$ & $51.0 \pm 2.18$ & $\mathrm{~ns}$ \\
\hline & \multicolumn{5}{|c|}{ ( $\mu$ moles of Trolox equivalent/100 g) } \\
\hline Antioxidant activity & $236.95 \pm 0.26$ & $13.5 \pm 0.38$ & $14.3 \pm 0.005$ & $22.7 \pm 0.02$ & $++^{* * *}$ \\
\hline
\end{tabular}

of the 7 polyunsaturated fatty acids C18:2n6, C20:2n6, and $\mathrm{C} 20: 5 \mathrm{n} 3$ increased linearly in response to increasing rice bran. In contrast, the percentage of total fatty acids of one polyunsaturated fatty acid C20:3n6 decreased linearly.

The $(\mathrm{C} 18: 0+\mathrm{C} 18: 1)$ to $\mathrm{C} 16: 0$ ratio did not vary significantly in response to the increasing rice bran percentages. Thus, the $(\mathrm{C} 18: 0+\mathrm{C} 18: 1)$ to $\mathrm{C} 16: 0$ ratio remained in the healthy range of 2-3 [10]. In this study, the ratio was from 2.72.9 across the rice bran percentages, which is in agreement with reported values [10]. The percentage of total saturated ( $\sum$ Sat) decreased linearly with increasing rice bran. The percentage of total MUFA and total PUFA increased linearly with increasing rice bran from $30.7 \%$ at zero percent rice bran to $33.4 \%$ at $3 \%$ rice bran. Subsequently, the percentage of total PUFA increased from $4.3 \%$ at zero percent rice bran to $5.2 \%$ at $3 \%$ rice bran. The percentage of total omega- 6 and total omega-3 in sausages increased linearly with increased rice bran from $3.97 \%$ and $0.31 \%$ at zero percent rice bran to 4.64 and $0.51 \%$ at $3 \%$ rice bran, respectively. These differences were significant $(P<0.05)$. The omega-3 to omega-6 fatty acid ratio (n3/n6) did not change significantly. The total DFA concentrations in this study increased linearly from $\% 73.2$ to $\% 74.5$ at zero percent rice bran to $3 \%$ of rice bran, respectively, which was not significant. These data are similar to data range presented by Banskalieva et al. [10]. In this study, the ratio of $\sum$ PUFA/ $\sum$ Sat was lower than in some reported literature [10] and similar to others [44]. The ratio of $\sum$ PUFA/ $\sum$ Sat increased linearly with increasing rice bran at a significant level $(P<0.001)$. This could be an additional health benefit of incorporating rice bran in the sausages. There was a linear increase in the fat percent of sausages in response to increasing rice bran percentages (Table 2). However, the percent of total saturated fatty acids decreased in response to increasing rice bran percentages of the sausages. The percentage of total unsaturated fatty acids, both MUFA and PUFA, and both total omega- 6 and omega-3, increased in response to increasing rice bran percentages.

3.3. $\alpha$-Tocopherol and Cholesterol Concentrations and Antioxidant Activity. The $\alpha$-tocopherol concentrations of rice bran and cooked sausages with added rice bran are presented in Table 4 . The concentration of $\alpha$-tocopherol in rice bran was
$7.37 \mathrm{mg} / 100 \mathrm{~g}$ which is similar to that presented in Gerhardt and Gallo [30] and Zigoneanu et al. [26]. The concentration of $\alpha$-tocopherol increased linearly in response to the increasing rice bran percentages of the sausages. High temperatures can cause $\alpha$-tocopherol degradation, but a previous study has shown no significant degradation with the cooking conditions used in this experiment [45]. The cholesterol concentration did not vary significantly in response to the increasing rice bran percentages. The antioxidant activity of unmixed rice bran and goat meat were 237.0 and 5.1 moles of Trolox equivalent per $100 \mathrm{~g}$, respectively. The antioxidant activity increased linearly from 13.5 to 22.7 moles of Trolox equivalent $/ 100 \mathrm{~g}$ in response to increasing rice bran percentages of the sausages (Table 4 ).

\section{Conclusions}

Goat meat sausages with 3\% of stabilized rice bran had higher concentration of $\alpha$-tocopherol, higher antioxidant activity, higher total omega 3/omega 6 ratio, higher total MUFA and total PUFA content, nonsignificant higher concentration of DFA, and an acceptable ratio of (C18:0 + C18:1) to C16:0 compared to zero percent rice bran. The $(\mathrm{C} 18: 0+\mathrm{C} 18: 1)$ to C16:0 ratio remained in the healthy range of 2 to 3 [10] across the rice bran percentages. Thus, sausages with added rice bran have a more beneficial fatty acid composition in regard to more mono- and polyunsaturated fatty acids as discussed in Section 3.2. Based on the results from this study and because of these factors, adding 3\% stabilized rice bran to goat meat sausage is recommended which will provide more health benefits.

\section{Conflict of Interests}

The authors declare that there is no conflict of interests regarding the publication of this paper.

\section{Acknowledgments}

This research was funded by USDA/NIFA Evans-Allen Grant no. 5-621567. The authors thank Christopher Rogers, Sanjay 
Palle, Curtis Chisley, Albert Howard, and Shaina Craige for their assistance in carrying out the study.

\section{References}

[1] J. S. Zheng, X.-J. Hu, Y. M. Zhao, J. Yang, and D. Li, "Intake of fish and marine n-3 polyunsaturated fatty acids and risk of breast cancer: meta-analysis of data from 21 independent prospective cohort studies," British Medical Journal, vol. 346, Article ID 13706, 2013.

[2] F as in Fat: How Obesity Policies Are Failing in America, Trust for America's Health, Washington, DC, USA, 2009, http://www.healthyamericans.org/.

[3] S. se Smet, K. Raes, and D. Demeyer, "Meat fatty acid composition as affected by fatness and genetic factors: a review," Animal Research, vol. 53, no. 2, pp. 81-98, 2004.

[4] J. R. Addrizzo, "Use of goat milk and goat meat as therapeutic aids in cardiovascular diseases," in Meat Goat Production Handbook. The Feasibility of Meat Goats in Minnesota, 507537-7440, Agricultural Utilization Research Institute, Marshall, Minn, USA, 2002, http://www.auri.org/.

[5] C. Ehnholm, J. K. Huttunen, and P. Pietinen, "Effect of diet on serum lipoproteins in a population with a high risk of coronary heart disease," New England Journal of Medicine, vol. 307, no. 14, pp. 850-855, 1982.

[6] N. L. Dawkins, O. Phelps, K. W. McMillin, and I. T. Forrester, "Composition and physicochemical properties of Chevon patties containing oat bran," Journal of Food Science, vol. 64, no. 4, pp. 597-600, 1999.

[7] L. K. Mahan and S. Escott-Stump, Krause's Food, Nutrition and Diet Therapy, pp. 59-61, W.B. Sanders, Philadelphia, Pa, USA, 1996.

[8] C. Devendra, in "Nutritional value of goat meat", International workshop on goat meat production in Asia, Tando Jam, Pakistan, March 1988.

[9] N. A. James, B. W. Berry, A. W. Kotula, V. T. Lamikanra, and K. Ono, "Physical separation and proximate analysis of raw and cooked cuts of chevron," in Proceedings of the 1990 International Goat Production Symposium, p. 22, October 1990.

[10] V. Banskalieva, T. Sahlu, and A. L. Goetsch, "Fatty acid composition of goat muscles and fat depots: a review," Small Ruminant Research, vol. 37, no. 3, pp. 255-268, 2000.

[11] United States Department of Agriculture (USDA), 1989, National Nutrient Data base, http://www.nal.usda.gov/.

[12] Packaged Facts, "Meat trends: culinary trends mapping report," Tech. Rep. LA182399, Market Research Group, Rockville, Md, USA, 2007.

[13] D. Giugliano, "Dietary antioxidants for cardiovascular prevention," Journal of Nutrition Metabolism and Cardio Vascular Diseases, vol. 10, no. 1, pp. 38-44, 2000.

[14] R. T. Nassu, L. A. G. Gonçalves, M. A. A. P. da Silva, and F. J. Beserra, "Oxidative stability of fermented goat meat sausage with different levels of natural antioxidant," Journal of Meat Science, vol. 63, no. 1, pp. 43-49, 2003.

[15] J. Kim and J. S. Godber, "Oxidative stability and vitamin E levels increased in restructured beef roasts with added rice bran oil," Journal of Food Quality, vol. 24, no. 1, pp. 17-26, 2001.

[16] J.-S. Kim, J. S. Godber, and W. Prinaywiwatkul, "Restructured beef roasts containing rice bran oil and fiber influences cholesterol oxidation and nutritional profile," Journal of Muscle Foods, vol. 11, no. 2, pp. 111-127, 2000.
[17] M. Serdaroglu, "The characteristics of beef patties containing different levels of fat and oat flour," International Journal of Food Science and Technology, vol. 41, no. 2, pp. 147-153, 2006.

[18] R. Brigelius-Flohe and M. G. Trabet, "Vitamin E: function and metabolism," Journal of the Federation of American Societies for Experimental Biology, vol. 13, pp. 1145-1155, 1999.

[19] E. M. Becker, L. R. Nissen, and L. H. Skibsted, "Antioxidant evaluation protocols: food quality or health effects," European Food Research and Technology, vol. 219, no. 6, pp. 561-571, 2004.

[20] D. Huang, B. Ou, M. Hampsch-Woodill, J. A. Flanagan, and E. K. Deemer, "Development and validation of oxygen radical absorbance capacity assay for lipophilic antioxidants using randomly methylated $\beta$-cyclodextrin as the solubility enhancer," Journal of Agricultural and Food Chemistry, vol. 50, no. 7, pp. 1815-1821, 2002.

[21] E. Niki and N. Noguchi, "Dynamics of antioxidant action of vitamin E," Accounts of Chemical Research, vol. 37, no. 1, pp. 4551, 2004.

[22] E. Niki, "Do free radicals play causal role in atherosclerosis? Low density lipoprotein oxidation and vitamin E revisited," Journal of Clinical Biochemistry and Nutrition, vol. 48, no. 1, pp. 3-7, 2011.

[23] M. Sugano and E. Tsuji, "Rice bran oil and cholesterol metabolism," Journal of Nutrition, vol. 127, no. 3, pp. 5215-5245, 1997.

[24] M. Diack and M. Saska, "Separation of vitamin E and $\gamma$ oryzanols from rice bran by normal-phase chromatography," Journal of the American Oil Chemists' Society, vol. 71, no. 11, pp. 1211-1217, 1994.

[25] B. J. Lloyd, T. J. Siebenmorgen, and K. W. Beers, "Effects of commercial processing on antioxidants in rice bran," Journal of Cereal Chemistry, vol. 77, no. 5, pp. 551-555, 2000.

[26] I. G. Zigoneanu, L. Williams, Z. Xu, and C. M. Sabliov, "Determination of antioxidant components in rice bran oil extracted by microwave-assisted method," Bioresource Technology, vol. 99, no. 11, pp. 4910-4918, 2008.

[27] R. M. Saunders, "Rice bran: composition and potential food sources," Food Review International, vol. 1, no. 3, pp. 465-495, 1985.

[28] M. Hegsted, M. M. Windhauser, S. B. Lester, and S. K. Morris, "Stabilized rice bran and oat bran lower cholesterol in humans," Nutrition Research, vol. 13, no. 4, pp. 387-398, 1993.

[29] R. J. Nicolosi, L. M. Ausman, and D. M. Hegsted, "Rice bran oil lowers serum total and low density lipoprotein cholesterol and apo B levels in nonhuman primates," Atherosclerosis, vol. 88, no. 2-3, pp. 133-142, 1991.

[30] A. L. Gerhardt and N. B. Gallo, "Full-fat rice bran and oat bran similarly reduce hypercholesterolemia in humans," Journal of Nutrition, vol. 128, no. 5, pp. 865-869, 1998.

[31] A. Ardiansyah, S. Hitoshi, K. Takuya, O. Kousaku, H. Katsumi, and K. Michio, "Rice bran fractions improve blood pressure, lipid profile, and glucose metabolism in stroke-prone spontaneously hypertensive rats," Journal of Agricultural and Food Chemistry, vol. 54, no. 5, pp. 1914-1920, 2006.

[32] B. E. McDonald, J. M. Gerrard, V. M. Bruce, and E. J. Corner, "Comparison of the effect of canola oil and sunflower oil on plasma lipids and lipoproteins and on in vivo thromboxane $\mathrm{A}_{2}$ and prostacyclin production in healthy young men," The American Journal of Clinical Nutrition, vol. 50, pp. 1382-1388, 1989. 
[33] National Institute of Health (NIH), "Celiac disease," NIH Publication 08-4269, 2008, http://digestive.niddk.nih.gov/ddiseases pubs/celiac/celiac_508.pdf.

[34] USDA/FSIS Directive, "Safe and suitable ingredients used in the production of meat, poultry, and egg products," pp. 43, 2013, http://www.fsis.usda.gov/OPPDE/rdad/FSISDirectives/7120.1 .pdf.

[35] G. Prabhu, "Meat binding wonder. Stabilized rice bran brings function and savings to meat processing," Asia Food Journal, September 2008, http://www.asiafoodjournal .com/article-5557-meatbindingwonder-asia.html.

[36] F. M. Ramezanzadeh, R. M. Rao, W. Prinyawiwatkul, W. E. Marshall, and M. Windhauser, "Effects of microwave heat, packaging, and storage temperature on fatty acid and proximate compositions in rice bran," Journal of Agricultural and Food Chemistry, vol. 48, no. 2, pp. 464-467, 2000.

[37] AOAC International, Official Methods of Analysis, AOAC International, Washington, DC, USA, 1995.

[38] D. Firestone, "Fatty acid composition by GLC, (marine oil)," in Official Methods and Recommended Practices of the AOCS, Section Ce 1b-89, AOCS Press, Champagne, Ill, USA, 4th edition, 1993.

[39] E. Katsanidis and P. B. Addis, "Novel HPLC analysis of tocopherols, tocotrienols, and cholesterol in tissue," Free Radical Biology and Medicine, vol. 27, no. 11-12, pp. 1137-1140, 1999.

[40] D. S. Oufnac, Z. Xu, T. Sun, C. Sabliov, W. Prinyawiwatkul, and J. S. Godber, "Extraction of antioxidants from wheat bran using conventional solvent and microwave-assisted methods," Journal of Cereal Chemistry, vol. 84, no. 2, pp. 125-129, 2007.

[41] SAS, SAS User's Guide. 12. 3, SAS Institute, Cary, NC, USA, 2004.

[42] F. Malekian, M. R. Rao, W. Prinyawiwatkul, W. E. Marshall, M. M. Windhauser, and M. Ahmedna, Lipase and Lipoxygenase Activity, Functionality, and Nutrient Losses in Rice Bran During Storage, Bulletin Number 870, Louisiana State University Agricultural Center, 2000.

[43] N. H. Casey, "Goat meat in human nutrition," in Proceedings of the 5th International Conference on Goats, vol. 2, no. 2, pp. 582598, New Delhi, India, 1992.

[44] P. A. Tshabalala, P. E. Strydom, E. C. Webb, and H. L. de Kock, "Meat quality of designated South African indigenous goat and sheep breeds," Meat Science, vol. 65, no. 1, pp. 563-570, 2003.

[45] C. M. Sabliov, C. Fronczek, C. E. Astete, M. Khachaturyan, L. Khachatryan, and C. Leonardi, "Effect of temperature and UV light degradation of $\alpha$-tocopherol in free and dissolved form," Journal of the American Oil Chemists' Society, vol. 86, no. 9, pp. 895-902, 2009. 

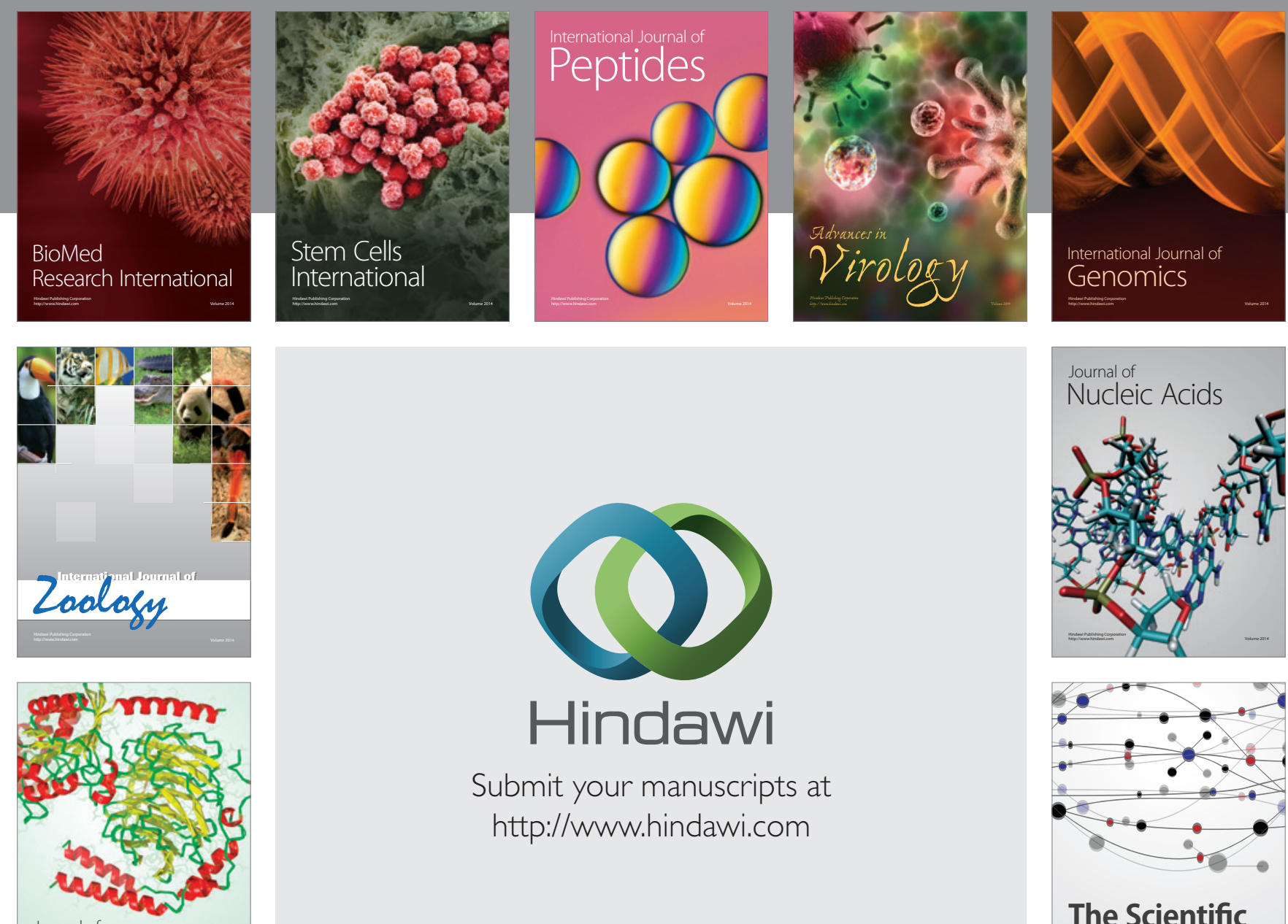

Submit your manuscripts at

http://www.hindawi.com

Journal of
Signal Transduction
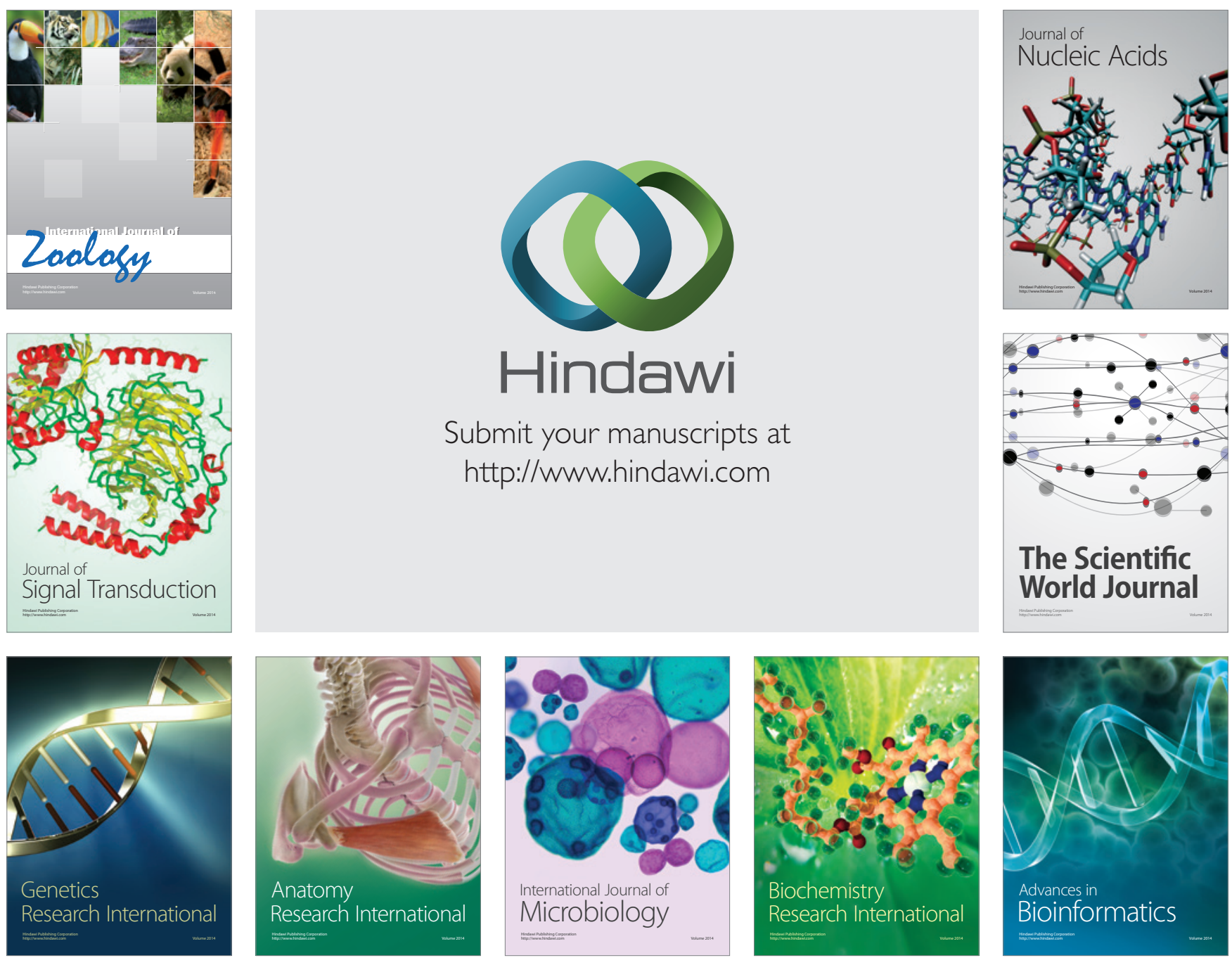

The Scientific World Journal
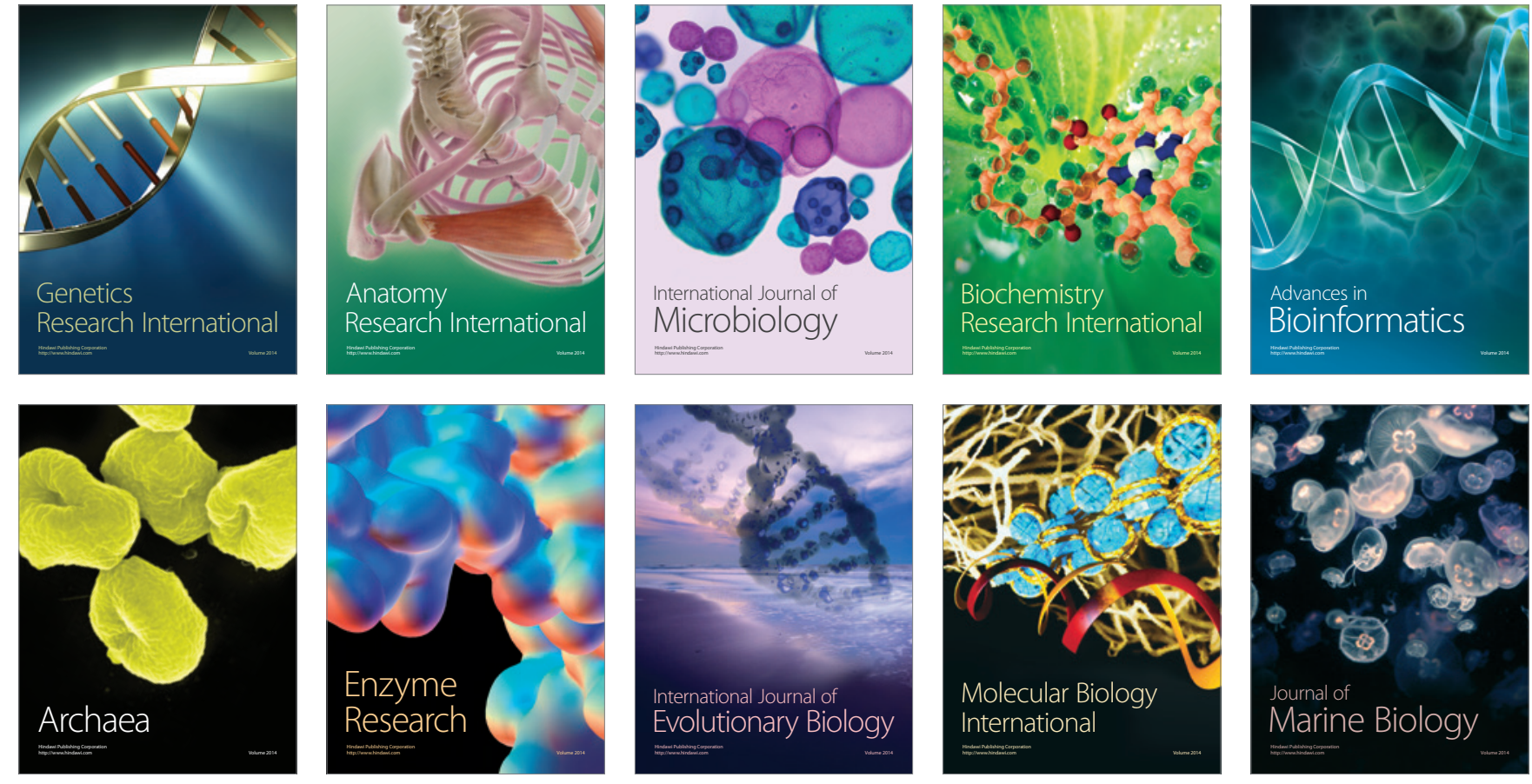